\title{
CARTOGRAFIA DAS INFÂNCIAS EM REGIÃO DE FRONTEIRA EM BELO HORIZONTE
}

\author{
SAMY LANSKY* \\ Maria Cristina Soares de GouvêA ${ }^{* *}$ \\ Ana Maria Rabelo Gomes*
}

\begin{abstract}
RESUMO: As crianças, como sujeitos sociais, lidam com o espaço conferindo-lhe significados próprios, a partir de diferentes dimensóes de sua identidade, entre elas a geracional. Se os espaços urbanos são via de regra construídos pelos adultos, nos processos de circulação são produzidas formas singulares de relacionar-se com a cidade pelos sujeitos infantis. Neste sentido, busca-se investigar como crianças vizinhas em uma mesma região urbana utilizam os espaços localizados na fronteira entre bairros de classe média e uma favela. Foi desenvolvida uma proposta de cartografia etnográfica dos "espaços com crianças", buscando apreender os usos (im) previstos e as brechas que encontram para se apropriar da cidade, apesar das demarcaçóes impostas pelo mundo adulto.
\end{abstract}

Palavras-chave: Criança. Infância. Cidade. Espaço público. Cartografia.

\section{CHILDHOOD CARTOGRAPHY OF AN URBAN BORDER IN BELO HORIZONTE CITY}

\begin{abstract}
Children, as social subjects, deal with space by assigning specific meanings to it, according to the different dimensions of their identity, one of them being age/generation. Urban spaces are usually built by adults, but, through an appropriation process, children as subjects produce unique ways of relating with the city. In this direction, this article presents data from an investigation carried out with neighbouring children of an urban region that explores how they appropriate the spaces located on an urban border between middle class neighbourhoods and a slum in Belo Horizonte. A proposal of an ethnographic cartography of the "space with children" was developed, in order to grasp the (un)predictable uses and the gaps that they could find in order to appropriate the city, despite the demarcations imposed by the adult world.
\end{abstract}

Keywords: Children. Childhood. City. Public Space. Cartography.

\footnotetext{
* Universidade Fumec e Centre Universitário Una, Belo Horizonte, Minas Gerais, Brasil. E-mail de contato: samy@lanskyarquitetura.com.br

** Universidade Federal de Minas Gerais, Faculdade de Educação, Belo Horizonte, Minas Gerais, Brasil.
} 


\section{CARTOGRAPHIE DES ENFANCES DANS UNE ZONE FRONTALIÈRE À BELO HORIZONTE}

RÉSUMÉ: Les enfants, en tant que sujets sociaux, interagissent avec l'espace en lui donnant des significations propres à partir de différentes dimensions de leur identité y compris la générationnelle. Si les espaces urbains sont normalement construits par les adultes, dans les processus d'appropriation, les sujets infantiles produisent des formes singulières par rapport à la ville. Dans ce sens, nous cherchons à analyser comment des enfants voisins, dans une même zone urbaine, s'en servent des espaces situés sur la frontière entre des quartiers de classe moyenne et une favela de Belo Horizonte. Une proposition de cartographie ethnographique "des espaces avec des enfants» a été développée, en cherchant à saisir les usages (im)prévus et les lacunes qu'ils trouvent pour s'approprier de la ville, malgré les démarcations imposées par le monde adulte.

Mots-clés: Enfant. Enfance. Ville. Espace public. Cartographie.

\section{Mapeando infâncias urbanas}

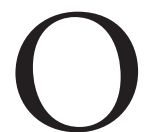

presente artigo apresenta uma cartografia de infâncias urbanas, buscando-se conferir visibilidade aos processos de circulação e trânsito de crianças em espaços urbanos contemporâneos. Para tal, foi realizado o estudo dos usos dos espaços públicos urbanos de uma região da cidade de Belo Horizonte por crianças moradoras dos bairros de classe média alta ou da favela que lhe fazia fronteira. Embora dividissem o mesmo território geográfico, tais crianças revelavam relaçóes distintas com o espaço público, definidas por seu pertencimento social, de gênero e idade.

Tal estudo, ao buscar dar visibilidade às distinçóes sociais no uso do espaço urbano pelas crianças, envolveu a construção de estratégias metodológicas de investigaçáo que permitissem observar, mapear e, principalmente, construir um registro cartográfico da relação que estes sujeitos tinham com tal espaço, resgatando sua perspectiva, o que denominamos etno-grafia espacializada.

Trata-se de uma investigação transdisciplinar, a partir do diálogo entre os estudos da sociologia e antropologia da infância ${ }^{1}$, antropologia, cartografia e planejamento urbano. Neste texto, iremos concentrar a análise na construção de estratégias metodológicas, bem como na descrição dos resultados sobre as diferenciaçóes no uso do espaço pelas crianças. Para tal, inicialmente será descrito o universo da pesquisa, caracterizando o espaço investigado e os sujeitos nele presentes. Posteriormente, serão apresentados os instrumentos metodológicos de desenvolvimento da investigação, no diálogo entre a antropologia e a cartografia. Por fim, serão analisadas as distinçóes nas formas de circulação e uso do espa- 
ço, apreensíveis pelos mapas, tendo como referência as diferenciaçóes sociais de classe, gênero e idade das crianças investigadas, e categorias trabalhadas no seu entrecruzamento. A investigação propóe-se a contribuir para um diálogo entre os estudos da infância e os estudos sobre a vida urbana, buscando apreender como a criança explora e circula pela cidade e neste processo constrói formas singulares de apropriação do espaço urbano definidas por sua identidade geracional. Mais exatamente, o foco foram os locais de proximidade da moradia, em uma região de fronteira entre diferentes classes sociais.

Embora essa circulação envolvesse em grande medida o percurso necessário para se deslocar até à escola, o foco da pesquisa era o trânsito e circulação pelos espaços públicos urbanos não-escolares, destacadamente as vias e o parque público da região.

A presença das crianças nas vias e no parque é marcante nessa região da cidade. Embora o espaço-tempo da escola fosse constitutivo da vida cotidiana dessas crianças, pois todas frequentavam a instituição, a pesquisa voltou-se para o tempo-espaço não-escolar, onde a cidade se oferece como lugar de experiência e exploração de diferentes aspectos da vida urbana. Tal perspectiva não desconsidera que a escola constitui também locus de formação e elaboração de experiências da vida urbana, mas tem em vista contemplar a singularidade das formas de participação na vida social características destes outros espaços.

Ao tratar da temática da criança no espaço urbano, cabe reiterar que o contraponto moderno-industrial entre vida pública (relacionada ao homem adulto) e vida privada (relacionada à mulher e à criança) deu origem à separação entre o universo adulto e o infantil (SENNET, 1988 [1974]) e significou o surgimento de uma série de espaços e objetos produzidos especificamente para as crianças, tais como as escolas, creches, parques, museus, dentre outros. Importante assinalar que tal contraponto não é universal, e não é encontrado em outros meios, como apontam diversos estudos sobre os povos indígenas brasileiros. (COHN, 2005; SILVA, 2011)

A criança urbana progressivamente tornou-se uma das principais vítimas da segregação socioespacial nas metrópoles modernas, resultando em casos de confinamento e/ou controle excessivo para alguns grupos e marginalização para outros. As condiçóes de acesso e uso dos espaços públicos (no caso de sociabilidade e lazer) são definidas tanto a partir das políticas estatais, quanto pelas diferenças socioeconômicas e culturais no desenvolvimento de uma sociabilidade urbana.

Neste sentido, estudos de urbanistas chamam atenção para a privatização dos locais de sociabilidade nas cidades brasileiras, em que as formas segregacionistas de lazer restringem as classes médias a espaços como shoppings, clubes e condomínios, "vedados" às camadas populares, estas circunscritas a espaços públicos precários e mal cuidados, demonizados como locais de perigo. 
(CALDEIRA, 2000; SOJA, 2000) As crianças experimentam, neste contexto, uma dupla segregação, quer pela visão do espaço público como inapropriado à circulação infantil, quer pela representação de sua periculosidade nas metrópoles brasileiras contemporâneas.

No entanto, a criança constitui sujeito que faz uso dos espaços públicos e constrói formas próprias de participação na vida urbana. Tais formas tomam expressóes distintas, em contextos socioculturais diferenciados. Assim é que Parga (2004) ressalta como as crianças dos países latino-americanos mostram-se mais presentes na cena urbana que crianças dos países europeus.

No caso brasileiro, o estudo da presença, circulação e usos dos espaços urbanos pelas crianças vem sendo contemplado nas investigaçóes da sociologia e antropologia da infância. O clássico estudo de Florestam Fernandes, As trocinhas do Bom Retiro (1944/2004), em que o autor buscou dar visibilidade às formas de uso dos espaços públicos pelas crianças paulistanas na década de 40, destacando as brincadeiras infantis, indicou um fértil campo de investigação. Este vem sendo desenvolvido de forma mais sistemática em produçóes mais recentes em que, a partir de estudos etnográficos, busca-se registrar e problematizar as distintas formas de participação na vida urbana de crianças de diferentes grupos sociais. ${ }^{2}$

O estudo que desenvolvemos insere-se nesta tradição, buscando conferir visibilidade a como no uso dos espaços pelas crianças estáo presentes as tensóes urbanas características das metrópoles brasileiras contemporâneas.

\section{A Barragem como espaço de fronteira}

Ao considerar que a desigualdade social brasileira imprime na cena urbana fronteiras na ocupação do espaço, buscamos dar visibilidade às zonas de fronteiras, quais sejam, locais de encontro e desencontro entre grupos sociais distintos. Para tal, estabelecemos como recorte espaciotemporal os arredores do Parque da Barragem Santa Lúcia em Belo Horizonte, localizado entre uma favela e um bairro de classe média alta - uma fronteira urbana (Figura 1).

Atualmente, Belo Horizonte é dividida em nove regionais administrativas, sendo que a Centro-Sul engloba toda a área do Plano Original elaborado por Aarão Reis no final do século XIX, alguns bairros "valorizados", a maior favela do município - o Aglomerado da Serra - e outras duas favelas, o Conjunto Santa Maria e o Aglomerado Santa Lúcia ou Morro do Papagaio (assim denominado pela população local). É, portanto, uma das regionais mais desiguais do município de Belo Horizonte, o que contextualiza a escolha de um espaço público nessa região para a pesquisa: região de uma metrópole onde a diversidade e a desigualdade sociocultural e econômica são marcantes. Num espaço de fronteira, um parque 
foi implantado próximo a um batalhão de polícia, uma escola pública, dentre outros equipamentos públicos e privados: o Parque Jornalista Eduardo Couri, ou simplesmente Barragem Santa Lúcia, como referido pelos moradores da regiáo.

\section{Figura 1}

Regional Centro-Sul de Belo Horizonte

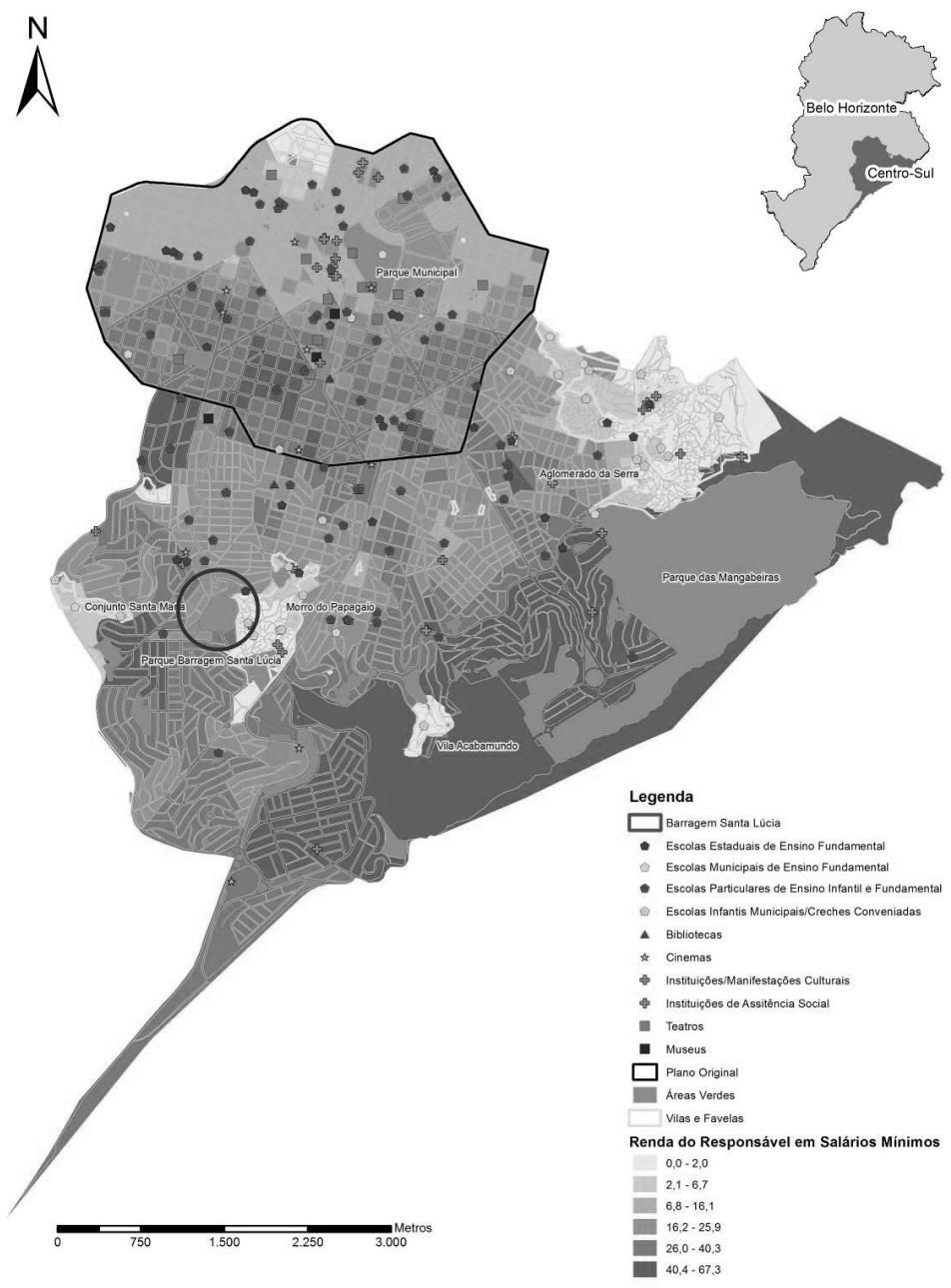

Fonte: Elaboração própria, com base nos dados do Censo Demográfico de 2000.

Nos arredores deste Parque, o contraste social é facilmente perceptível, característica própria dos locais onde favelas fazem fronteira com bairros de classe 
média nas metrópoles brasileiras. A fronteira neste estudo é, portanto caracterizada pela linha da desigualdade socioeconômica perceptível pela observação das diferentes formas de morar, usar os espaços públicos, consumir e circular dos moradores. Apesar de visível, a fronteira apresentava-se muito porosa, onde os usos dos espaços pelos moradores dos bairros e do Morro se cruzavam em ocasióes que foram exploradas nesta investigação.

A expressão espaços com crianças busca contrapor-se à concepção de espaços infantis especializados, espaços de ou para crianças. Ou seja, buscou-se neste estudo apreender a presença das crianças tanto nos espaços produzidos por adultos para o uso infantil, como o parque em questão, quanto a circulação por vias públicas no entorno do mesmo. Além disto, tal expressão busca destacar a participação ativa das crianças na coleta de dados. Para Gulløv e Olwig (2003) a criança usa tais locais adultos como espaços de resistência. Para os adultos, tais espaços são inadequados para circulação das crianças sem sua presença ou mesmo potencialmente disruptivos, restringindo sua circulação. Porém, (e também por isto mesmo) exercem atração entre os grupos infantis, que os utilizam a partir de uma lógica própria.

Para buscar apreender e fazer o registro da circulação e trânsito das crianças neste espaço, adotou-se como procedimento metodológico o movimento a pé pelas ruas da vizinhança do parque, a circulação pelos lugares, num experimento de mudança de perspectiva e de confronto entre a posição social do pesquisador - adulto e arquiteto - e a dos sujeitos - pobres e ricos, adultos, idosos, jovens, meninos e meninas, todos usuários dos arredores do Parque. A pesquisa sobre co-presença, sociabilidade e o encontro desses sujeitos num espaço público urbano contemporâneo efetivou-se através do movimento de circulação entre um mundo e outro, em suas fronteiras, que descreveremos a seguir.

\section{A construção de uma etno-grafia espacializada}

Como procedimento metodológico da observação participante, foi adotada a interação direta do pesquisador sem a mediação de qualquer instituição ou de pessoa previamente conhecida por este. Em ambiente tido como hostil, representação característica de espaços públicos urbanos, buscou-se experimentar as possibilidades de interação, suas expressões e demarcação espacial, as zonas de fronteira, bem como as interdições, barreiras e conflitos, construindo uma brecha ou espaço de interstício.

Nesse sentido, o pesquisador se expóe como transeunte, tentando calcular e correndo os riscos próprios da atitude de estar em público num espaço de fronteira. Ao se deslocar a pé pelo campo e se posicionando distintamente, aos 
poucos foram encontradas formas de conhecê-lo, mediante a interação com os sujeitos da pesquisa. Inspirado em De Certeau (1994 [1990]), para quem o ato simples de andar pela cidade pode revelar sentidos e apropriaçóes atribuídos ao espaço para além da ordem dominante, Lopes (2005, p. 72, grifos do autor) evoca a metodologia andante:

Importa reiterar o quanto andar desafia o medo da cidade e as gestóes políticas desse medo, impondo, passo a passo, o direito de transgredir fronteiras sociais e simbólicas, acabando com as cidades interditas, os bairros do estigma, as separaçóes 'naturais', 'puras' e 'fixas', as abstracçóes do outro como excluído e marginal, a descoincidência, tantas vezes demonstrada, entre a (in) segurança subjectiva e a (in)segurança objectivamente medida. Aliás, é pela transgressão de fronteiras e pelo mover-se na fronteira que as legitimidades dominantes vão sendo, a diversos níveis, questionadas. (LOPES, 2008, p. 78, grifos do autor)

Ingold (2000) considera que o conhecimento sobre o ambiente sofre formação contínua durante o movimento das pessoas pelo mesmo. Conhece-se enquanto caminha-se: "Unidos pelos itinerários de seus habitantes, os lugares existem não no espaço, mas, como nós, em uma matriz de movimento". (INGOLD, 2000, p. 219) Segundo o autor,

[...] enquanto seria errado, ou pelo menos enganoso, comparar o conhecimento do nativo a um mapa, há certo paralelo que pode ser traçado entre os processos de conhecer e de mapear. Ambos são atividades situadas no ambiente, ambos são realizados ao longo de trilhas de circulaçáo, e ambos se desenvolvem ao longo do tempo. (INGOLD, 2000, p. 220)

O recurso ao trânsito como procedimento metodológico de investigação não significa considerar tal movimento como igual ao do sujeito que caminha e conhece o espaço através deste transitar. Tal analogia não constitui uma identidade, mas reveste-se da mesma intensidade que caracteriza a imersão etnográfica em que o próprio pesquisador, na interação com as pessoas e com o ambiente, produz em primeira mão os dados sobre os quais deve depois se debruçar. (GEERTZ, 1976, 1997) O trânsito realizado pelo pesquisador permitiu repercorrer, junto com as crianças, o percurso realizado por elas mesmas; além de registrar as informaçóes que os próprios sujeitos da investigação traziam enquanto circulavam naquela região da cidade.

O registro cartográfico teve em vista, o que Ingold considera “[...] um paradoxo no coração da cartografia moderna. Quanto mais ela procura prover uma representação exata e abrangente da realidade, menos verdadeira esta re- 
presentação parece”. (INGOLD, 2000, p. 242) Nessa perspectiva, os mapas moderno-científicos apresentam uma lacuna na representação gráfica do espaço, ao desconsiderar a jornada realizada pelos cartógrafos. Eliminam-se dos mapas as rasuras e práticas de sua produção, como se estes não dependessem de nenhum ponto de vista. (TURNBULL 1996 apud INGOLD, 2000, p. 229)

Em contraponto à cartografia moderna que pretende a produção de representaçôes exatas e objetivas do mundo, Ingold prefere a ideia de que conhecemos o ambiente enquanto caminhamos; e que o viajante que conhece enquanto caminha não está elaborando um mapa, nem utilizando um. Assume, assim, a ideia de "cartografia de processo" de Rundstrom (1993, apud INGOLD 2000, p. 231), no qual mapear é visto como um movimento "[...] aberto, contínuo, sempre levando ao próximo instante do mapear, ao próximo mapa”, constituindo-se numa narração verbal das jornadas efetuadas ao longo do tempo. Segundo Ingold (2000, p. 231) elaborar mapas não é mapear. Aquele que conhece enquanto caminha não está elaborando nem utilizando mapas, está "simplesmente mapeando". Ao se desconsiderar o movimento dos habitantes no mapa moderno, são deixados de lado todos seus movimentos e práticas, como se nada acontecesse nesses espaços, e como se a representação deles antecedesse a presença das pessoas. Trata-se de espaços tornados conceitualmente vazios.

Neste sentido, os mapas etno-gráficos utilizados como escrita neste artigo são distintos dos mapas utilizados na cartografia tradicional, por se referirem aos sujeitos (etno). Eles não podem ser considerados figuras estáticas, acabadas, pois apresentam o processo em andamento e as ferramentas utilizadas. Provavelmente os cartógrafos e geógrafos diriam que não são mapas, mas simples figuras, ou croquis.

A busca por uma espacialização dos dados - uma escrita que lançasse mão tanto de recursos textuais quanto de imagens referidas ao espaço para reconstruir os conhecimentos e práticas dos sujeitos - foi central neste trabalho. Propôs-se elaborar um outro tipo de leitura, alterando a perspectiva e os modos de analisar os espaços públicos de grandes cidades. A exploração de um possível registro gráfico espacializado permitiu progressivamente a construção de um posicionamento singular, que alternava posiçóes, e exigiu a busca por outras formas de proceder com as notas de campo. Este conjunto de elementos, de alternância de posicionamentos, de perspectivas e de registro gráfico foi denominado neste estudo, etno-grafia espacializada.

Ao circular pelos arredores da Barragem Santa Lúcia, era necessário encontrar brechas onde a pesquisa fosse possível, uma possibilidade de estar em campo diante da violência e a prioridade dada ao trânsito de automóveis em detrimento da circulação das pessoas; da normatização e privatização dos usos dos espaços públicos de lazer; a luta pela sobrevivência e as formas de resistência dos 
moradores do aglomerado diante das contínuas agressóes a que estão submetidos, numa sempre tensa relação de disputa por um lugar na cidade, diante da ameaça real que a violência urbana impóe.

Foi ainda necessário encontrar uma brecha possível para estudar as crianças nos espaços públicos numa interação direta que impunha dificuldades dadas as diferenças culturais, sociais e etárias entre o pesquisador e os sujeitos infantis.

Além disso, tal presença se distinguia de acordo com a inserção social dos grupos estudados e refletia nos modos como viam o pesquisador, o recebiam ou não em campo. Nos extremos, enquanto algumas crianças dos bairros experimentavam o controle excessivo ou confinamento, ou seja, eram quase ausentes na cena, algumas moradoras do aglomerado experimentavam a vulnerabilidade $\mathrm{e}$ completa exposição à violência, tendo sido muito presentes no local da pesquisa. No entanto, apesar das formas de controle e de imposiçáo de modos de vida, ambos os grupos de crianças encontravam suas brechas e alteravam, de forma própria, o ambiente e as relaçóes com o mesmo.

Especialmente algumas crianças moradoras do aglomerado criavam suas formas próprias de estar no local, circulando com muito mais desenvoltura do que o pesquisador. Não só não tinham medo de serem assaltadas, como extraíam das oportunidades de interação com o outro, formas próprias de (sobre)viver. Por meio dessas habilidades adquiridas no cotidiano, elas participavam como atores na produção de seus lugares. Se, por um lado experimentavam a violência urbana na carne e de pé no chão, por outro aprendiam a circular pelos espaços, a brincar entre pares, a fazer amigos nos espaços públicos e com jogo de cintura "se viravam", encontrando suas brechas.

Inspirados nas suas analogias das interaçôes humanas com a dramaturgia realizadas por Goffman (1959), fez-se um estudo da cena, tempo-espaço em que uma atividade ocorre, cujo cenário é o espaço urbano público aberto e que o pesquisador imprime atenção especial na interação das pessoas. A cena foi, neste estudo, a unidade de análise utilizada para a organização e o registro da observação de campo nos arredores da Barragem Santa Lúcia e foi associada à presença de crianças em um local e um momento específico do dia e ao tipo de atividade desenvolvida, bem como a presença de brinquedos, equipamentos e demais elementos do ambiente.

As crianças e seus acompanhantes presentes nas cenas foram classificadas por gênero, faixa etária, local de moradia (bairros, favela ou não moradoras dos arredores), se estavam no espaço entre pares ou se estavam a sós. O foco deu destaque aos meninos e meninas entre 6 e 12 anos aproximadamente, sem deixar, no entanto, os outros atores na "sombra".

Em busca da espacialização da etnografia, o diário de campo foi transcrito, as cenas numeradas, categorias e aspectos relevantes destacados e os dados 
foram organizados em planilhas. Essa opção por organização dos dados teve como objetivo a utilização das informações em programa de geoprocessamento, o Sistema Geográfico de Informaçóes (GIS - Geographic Information System).

Os dados apresentados se referem à primeira entre as duas fases da observação em que foram realizadas incursóes em distintos dias da semana, horários e espaços, com o objetivo de identificar a presença de crianças, a circulação e os usos dos espaços por elas. A recorrência de certas presenças e situaçóes acionou interlocuçôes aproximadas com algumas crianças, que foram acompanhadas em suas brincadeiras, conversas, no deslocamento e demais atividades.

Nessa primeira fase de observação, foram 88 dias de campo descritos em diário. Além da circulação pelos arredores da Barragem Santa Lúcia, adotou-se os seguintes procedimentos para coleta de dados: visitas ao Morro, circulação pelas padarias e outros estabelecimentos comerciais, academias de ginástica; conversas com diversos usuários desses espaços; coleta de informaçóes e folders a respeito do funcionamento dos prestadores de serviços; observação em torno de algumas das escolas particulares dos bairros Santa Lúcia e São Bento.

No total, foram registradas 266 cenas, observadas entre maio de 2009 a agosto de 2010, em dias da semana e horários variados, incluindo os finais de semana e feriados. Nessas cenas foi registrada a presença das crianças nos espaços públicos, acompanhadas ou não por seus pares e/ou por adultos, assim como foram registradas as atividades por elas desenvolvidas. Dentro do grupo de crianças que compunham as cenas, foi destacado um grupo de 11 crianças entre 6 e 11 anos ( 4 meninas e 7 meninos), todas moradoras do Morro do Papagaio, as que mais assiduamente frequentavam o parque e que configuravam um grupo de sociabilidade infantil. Com essas crianças foram realizadas 12 seções de fotos e 2 filmes curtos. Além disso, foram realizadas 16 entrevistas informais. colunas:

A partir das cenas registradas, foi montada uma tabela com as seguintes

- Cena: tempo-espaço em que ocorre a presença de pessoas;

- Turno: período do dia em que ocorre a cena;

- Local: onde acontece a cena. Esse território é definido pelo(s) elemento(s) que o caracterizam e que se relacionam com a ocorrência de certo(s) uso(s), ou seja, uma característica do ambiente, equipamento ou um mobiliário urbano intimamente ligado à ação e ao(s) uso(s) de tal espaço;

- Pessoas: os dados levantados levaram em conta a faixa etária, gênero, local de moradia; 
- Acompanhantes: subcategoria associada às crianças que qualifica a presença delas no espaço, segundo a presença ou não de outra pessoa acompanhando-as; a categorizaçáo dos acompanhantes leva em conta a inserção geracional, gênero, moradia e foram abreviados na planilha da mesma maneira descrita acima; quando eram da mesma faixa etária e moradia, foram considerados "pares". Foram observadas crianças: sozinhas, entre pares, acompanhadas de jovem(ns), de adulto(s), de idoso(s) e da família;

- Dados complementares receberam colunas específicas na planilha: tipo de atividade; brinquedo ou brincadeira presente na cena; equipamento, mobiliário ou característica do espaço que interfere na cena; aspectos relevantes ou destaques; categoria temática relativa à cena observada; discurso local, ou seja registro da fala dos sujeitos na cena em curso; e fontes, que indica ou não se foram produzidos outros tipos de informação, tais como fotos, desenhos ou entrevistas.

Além da busca por categorias locais e aspectos recorrentes, essa opção por organização dos dados teve como objetivo a utilização das informaçóes em programa de geoprocessamento.

\section{Distinções sociais no uso do espaço urbano pelas crianças}

Os mapas apresentados a seguir resultam da espacialização das 266 cenas com crianças lançadas no programa ArcGis sobre foto de satélite extraída do Google Earth e se diferem pelos filtros aplicados às planilhas que geraram o geoprocessamento, que variaram de acordo com o local de moradia, gênero e faixa etária. Com base no geoprocessamento das cenas foi utilizado o Kernel - comando do programa ArcGis que analisa os dados e representa, por meio de manchas, as densidades de determinados fenômenos. Como resultado, observam-se manchas que variam entre o vermelho e o azul, dependendo da quantidade de cenas observadas, neste caso, as cenas com crianças. Como exemplo, no mapa de densidade de cenas com crianças moradoras do Morro (Figura 2), foram representadas 143 cenas.

Entre estas, 31 cenas entre o Coco e a Biquinha, 26 cenas na Quadra/ Parquinho e cinco cenas no Campo, representadas através da gradação de cores no mapa. Em outras palavras, as manchas nestes mapas representam graficamente os espaços nos arredores da Barragem Santa Lúcia que as crianças usavam com mais recorrência. 


\section{Figura 2}

Densidade de cenas com crianças moradoras do Morro do Papagaio

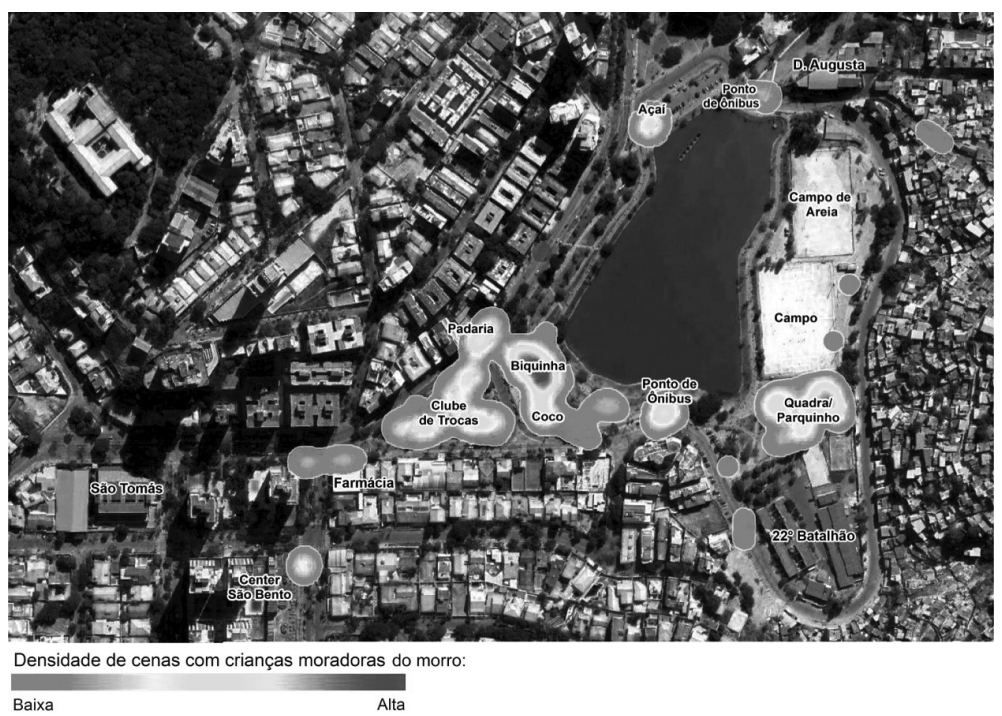

Fonte: Elaboração própria a partir de dados do autor.

Na primeira análise comparativa do local de moradia (Figuras 2 e 3), foi possível concluir que a presença das crianças dos bairros nos espaços públicos dos arredores da Barragem Santa Lúcia era bem distinta da presença das crianças do aglomerado. Ao considerar que os horários de tempos não escolares desses grupos pouco diferiam, pois a permanência na instituição, bem como os horários de entrada e saída eram muito parecidos, verifica-se que os tempos de circulação e as oportunidades possíveis de usarem os espaços públicos coincidiam. Além de um primeiro turno em escolas, tanto as crianças moradoras dos bairros quanto as do aglomerado participavam de atividades complementares no segundo turno, mesmo frequentando espaços distintos. Enquanto as crianças do Morro permaneciam nas escolas em tempo integral ou participavam, no segundo turno, de programas ofertados por instituiçóes religiosas, não governamentais e de assistência social, as dos bairros frequentavam escolas privadas de línguas, de dança, de futebol, academias ou clubes. Ou seja, observa-se que os tempos dedicados às atividades relacionadas à cultura escolar, projetavam-se para além do horário escolar strictu sensu em ambos grupos. 


\section{Figura 3}

Densidade de cenas com crianças moradoras dos bairros

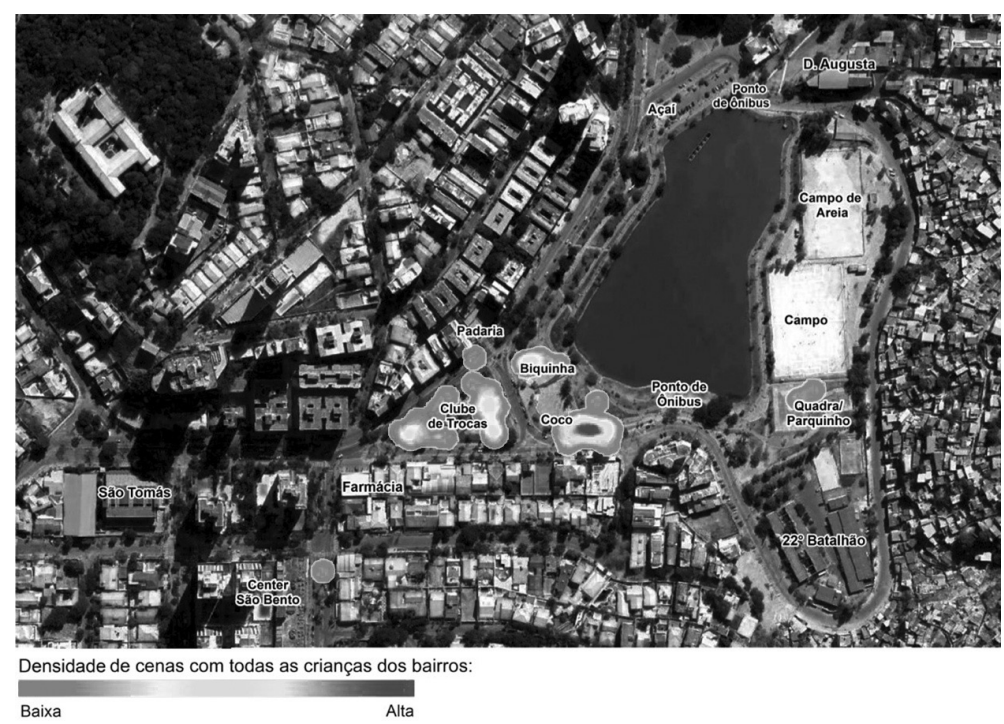

Fonte: Elaboração própria a partir de dados do autor.

A presença de crianças na Barragem Santa Lúcia distinguia-se de maneira clara e recorrente. As crianças moradoras dos bairros foram observadas em ocasióes espaço-temporais específicas e invariavelmente acompanhadas por adultos. Já entre as crianças moradoras do aglomerado observavam-se variaçôes, em que algumas eram acompanhadas por adultos, principalmente nos finais de semana, outras invariavelmente entre pares e desacompanhadas de jovens e adultos.

É possível considerar, então, que, apesar de vivenciarem de maneira muito semelhante a organização de seus tempos (visto que são definidos principalmente pelos tempos escolares) e da coabitação na região do Santa Lúcia, as crianças dos distintos grupos sociais pouco cruzavam umas com as outras e, portanto, pouco se conheciam. Em outras palavras, como sujeitos de um único grupo geracional, mas que não participavam do mesmo grupo social, as crianças moradoras da região pesquisada experimentavam uma segregação do tipo intrageracional e interclasses.

No que tange às relaçóes de gênero, se comparada a densidade de cenas com meninos e meninas moradores do aglomerado por meio dos mapas (Figuras 4 e 5), observa-se que as distinçóes eram menos visíveis e ocorriam, principalmente, no espaço da quadra/parquinho e em frente à padaria. No caso da quadra/parqui- 
nho, esse fato se deve, principalmente, ao uso da quadra para a prática do futebol, visivelmente associado aos meninos. No caso do espaço em frente à padaria, as meninas foram observadas com maior intensidade, em atividades de busca pelo recurso ao pedir dinheiro e comida aos adultos que estacionavam nos passeios e compravam.

\section{Figura 4}

Densidade de cenas com meninas moradoras do Morro do Papagaio

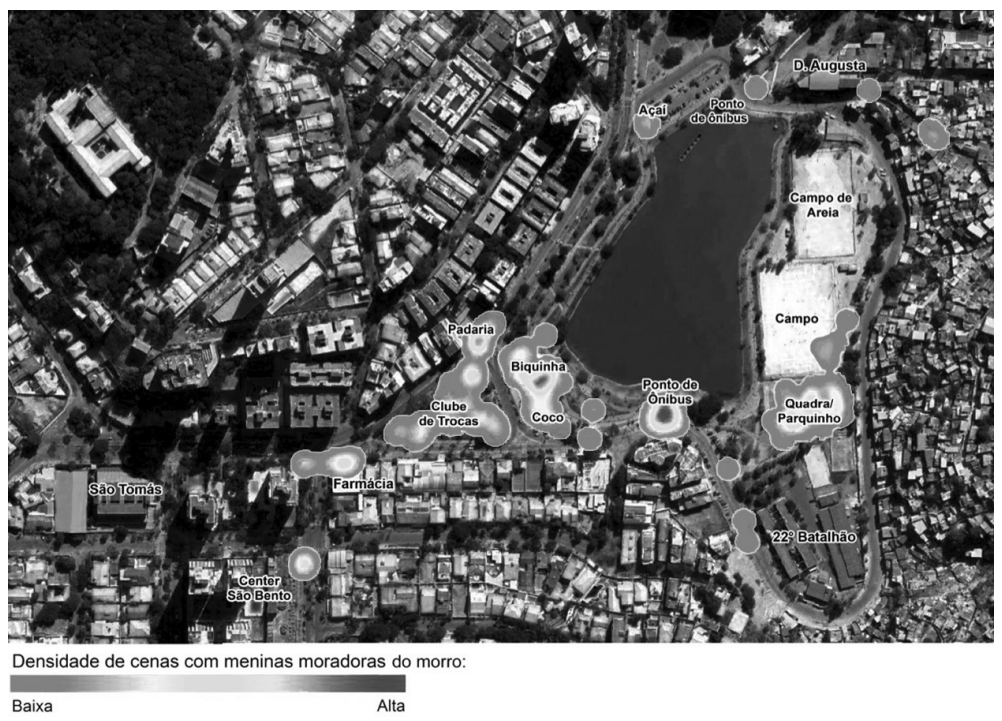

Fonte: Elaboração própria a partir de dados do autor.

Ao comparar a presença das crianças moradoras dos bairros segundo a faixa etária, observamos crianças maiores (entre 8 e 10 anos) no Clube da Troca de figurinhas e as pequenas (entre 0 e 4 anos) pelas manhãs entre o coco e a "biquinha" (Figuras 6 e 7). Nesses horários, as crianças maiores dos bairros foram observadas nas escolas de idiomas e na academia, ou em aulas de natação.

O Clube da Troca de figurinhas é realizado há mais de uma década pela banca de revistas existente no local. Reunia muitas pessoas, especialmente as crianças de ambos os grupos sociais do entorno. Os meninos eram mais presentes, visto o apelo do jogo a esse grupo e a atração que lhes causava. Nos finais de tarde, mas especialmente aos sábados pela manhã, os meninos dos bairros iam até a "pracinha" de carro com os pais, se encontravam e interagiam com desconhecidos em situaçóes que serão abordadas aqui. 


\section{Figura 5}

Densidade de cenas com meninos moradores do

Morro do Papagaio

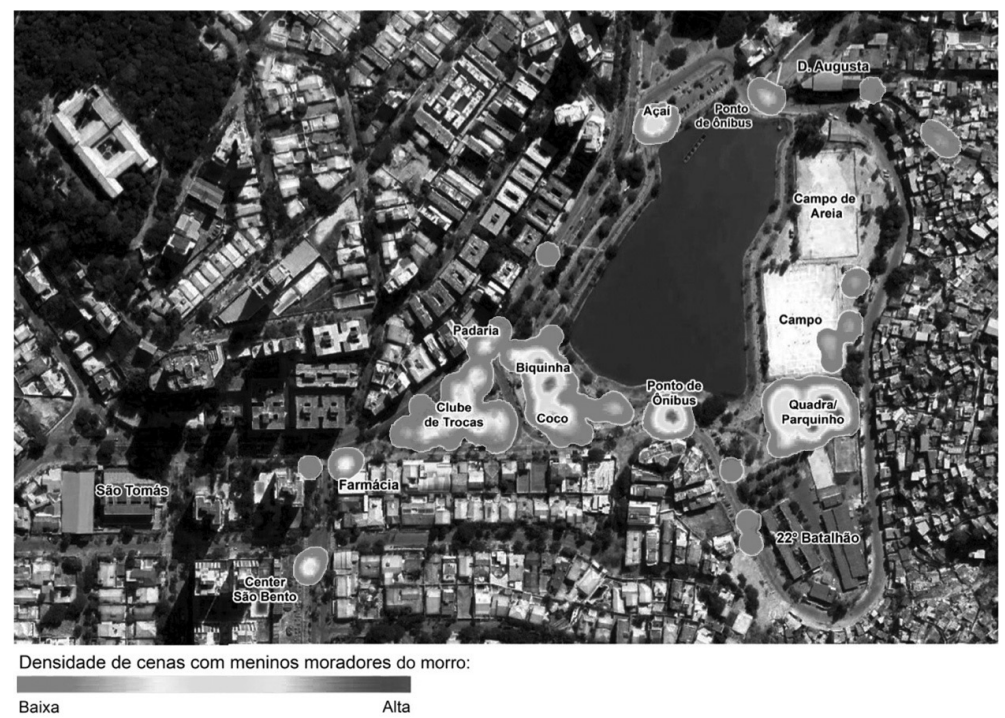

Fonte: Elaboração própria a partir de dados do autor.

\section{Figura 6}

Densidade de cenas com crianças pequenas dos bairros

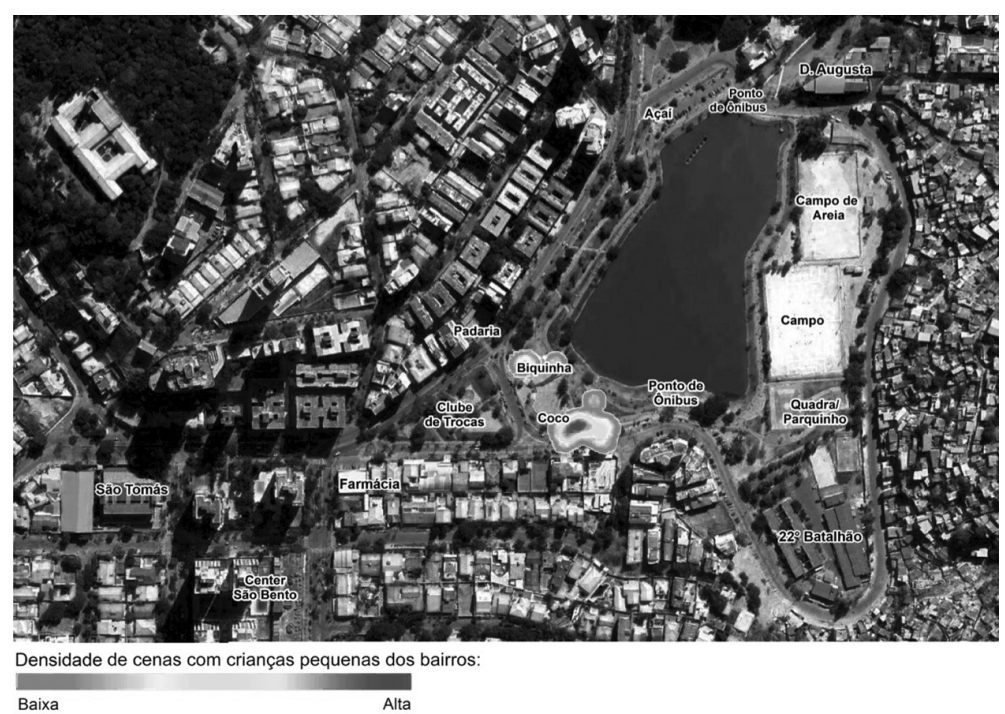

Fonte: Elaboração própria a partir de dados do autor. 


\section{Figura 7}

Densidade de cenas com crianças maiores dos bairros

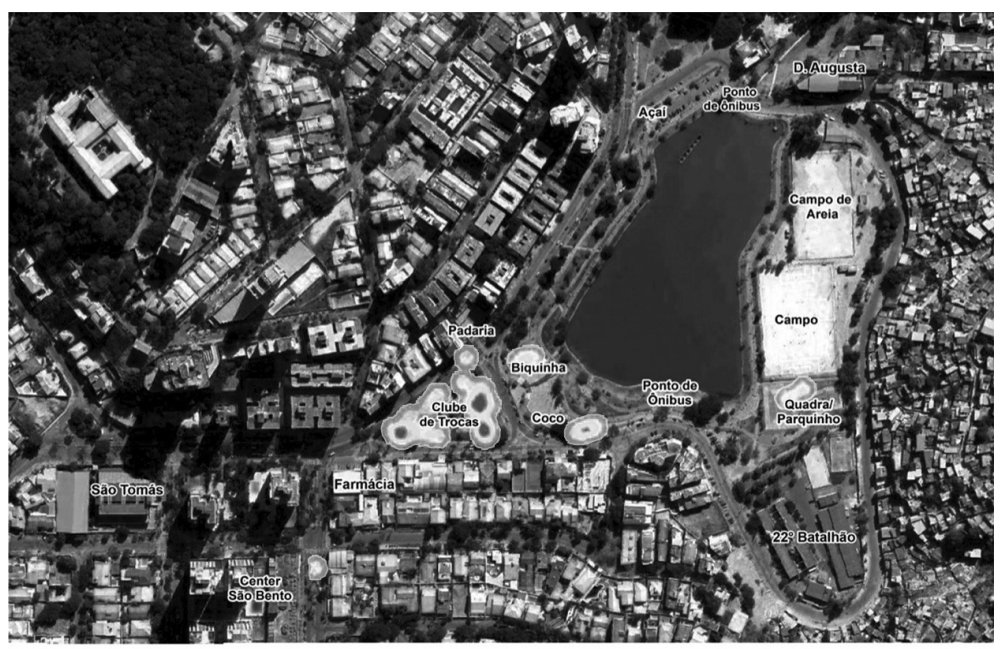

Densidade de cenas com crianças maiores dos bairros:

Baixa

Fonte: Elaboração própria a partir de dados do autor.

Figura 8

Densidade de cenas com todas as crianças

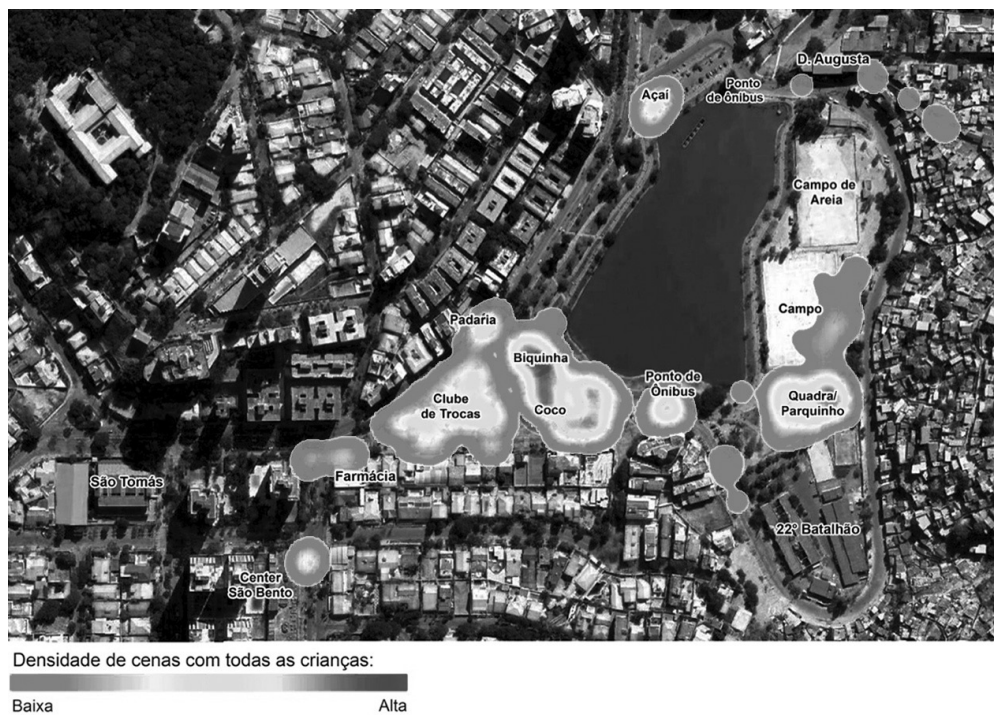

Fonte: Elaboração própria a partir de dados do autor. 
Ao registrar todas as cenas com crianças na Barragem Santa Lúcia, obteve-se o mapa da Figura 8. É possível constatar a forte presença de crianças nos diversos locais observados. Em alguns desses locais, essa presença era ainda mais evidente e visível: no Clube da Troca da "pracinha", entre o coco e a "biquinha", nos arredores da quadra pequena e do parquinho e em frente à drogaria, à farmácia e ao centro comercial.

\section{O Clube da Troca}

Se no cotidiano do Parque a ocupação e uso do espaço mostravam-se rigidamente definidos a partir do pertencimento social dos usuários, um espaço-tempo rompia, ainda que de forma limitada com as barreiras sociais, a partir do desenvolvimento de uma atividade ligada a cultura infantil contemporânea, o que descrevermos a seguir.

Trata-se do Clube da Troca de figurinhas que acontecia mediante um regulamento e horários estabelecidos pela banca de revistas existente no local. Como dito, reunia muitas pessoas, no entanto, nesta convivência, as formas de apropriação do espaço e os significados impressos ao jogo pelas crianças do Morro e pelas dos bairros eram distintas.

A presença das crianças dos bairros, especialmente meninos, era mais visível, ao contrário dos outros horários em que a presença das crianças do aglomerado era dominante. Em torno da atividade da troca de figurinhas, estas crianças participavam muitas vezes apenas como espectadores. Porém, a atração que o espaço exercia era evidente, levando-as a procurar brechas para brincar com autonomia, resultando numa relação em que os adultos tinham de se esforçar para acompanhá-los, enquanto trocavam figurinhas dos álbuns dos filhos. Tanto meninas quanto meninos dos bairros não foram observados entre pares; estavam sempre na companhia de jovens ou de adultos, presença claramente distinta se comparada com a presença das meninas e meninos do Morro, ambos presentes entre pares em todas as ocasióes observadas.

A entrada de meninos e meninas do aglomerado no jogo acontecia de forma distinta, pois era necessário um investimento financeiro para participar. No início, observavam, tentavam ajudar os meninos dos Bairros e acabavam entrando na brincadeira ao receberem as figurinhas repetidas daqueles que completavam os álbuns. A partir daí passavam a trocá-las e a vendê-las, a participar do jogo e da troca. As crianças do Morro encontravam, portanto, uma abertura e se tornavam jogadores, ao buscar as figurinhas para outros, trocá-las, vendê-las e jogar. A troca tornou-se, nesse contexto específico, partilha, interação e copresença no espaço; no entanto, grupos distintos ocupavam papéis também distintos no jogo. 
Os objetivos e significados impressos ao jogo eram igualmente distintos se comparados os grupos. Para as crianças dos bairros, o jogo tinha significado enquanto tal; já para as do aglomerado, além da brincadeira, significava acesso a recursos financeiros. Cabe destacar também a participação de diversas gerações na atividade e a forma como as interaçóes ocorriam, em que esta expressão da cultura infantil era incorporada à sociabilidade e cultura adulta urbana. (CORSARO, 2002)

O Clube da Troca revelou, ainda, a presença marcante e a importância do jogo na cidade. (LEFEBVRE, 2009 [1968]) Enfatize-se que ocorria - apesar das complexas nuances presentes - interação intergeracional e interclasses, promovida por um estabelecimento comercial privado e que, para além das relaçóes em torno da busca por recursos, possibilitaria ou criaria uma oportunidade para que um encontro entre grupos etários e sociais distintos ocorresse por meio de um jogo no espaço público.

\section{A circulação no espaço urbano}

\section{Figura 9}

Fluxos de circulação das crianças do Morro nos arredores da Barragem Santa Lúcia

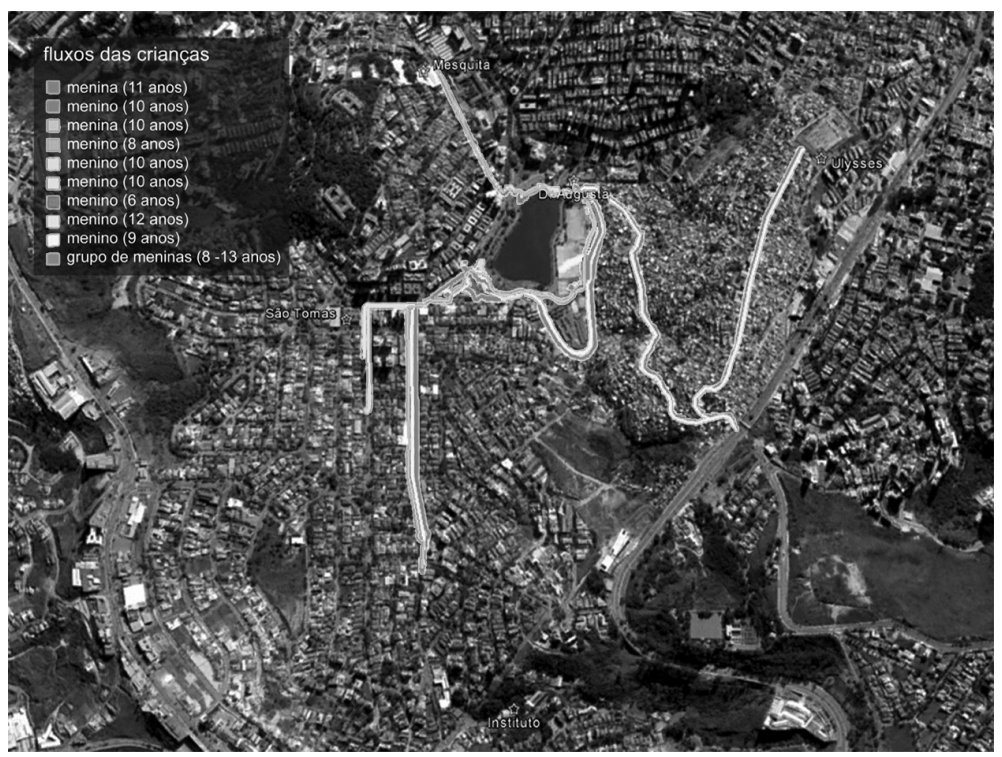

Fonte: Elaboração própria, através do programa Google Earth. 
Os mapas de fluxos do movimento das 11 crianças do Morro investigadas foram realizados mediante a marcação das diversas cenas em que cada uma dessas crianças foi observada. Esse exercício de mapeamento revelou, portanto, os locais nos arredores frequentados por essas crianças e os caminhos que faziam entre um espaço e outro, principalmente a pé e de bicicleta. $\mathrm{O}$ recorte espacial adotado assumiu a Barragem Santa Lúcia como centro e as diversas escolas, como os limites da observação realizada para esta investigação. O primeiro mapa, numa escala mais ampla, demonstra a circulação das crianças por toda a região pesquisada (Figura 9) e o segundo estabelece um zoom nos arredores da Barragem Santa Lúcia (Figura 10). Ressalte-se que a moradia dessas crianças, todas localizadas no Morro do Papagaio, não foram representadas nestes mapas, para não identificá-las.

Ao representar a circulação das crianças pelos espaços como linhas, representamos - inspirados em Ingold (2011) - o movimento que realizavam ao longo do tempo e o entrelaçado de suas jornadas de vida. Ao se referir ao emaranhado tecido pelas linhas de movimento das pessoas, animais, plantas e coisas, Ingold (2011) contesta a ideia de ligação entre pontos que o conceito moderno de transporte urbano adota e, portanto, questiona a metáfora das redes (networks) que essas linhas formariam. Nesse sentido, prefere tomar emprestado o termo meshwork, de Lefebvre (1991 [1974], p. 117-118):

Existe algo em comum, observa Lefebvre, entre o modo como as
palavras são inscritas sobre uma página escrita e o modo como
os movimentos e ritmos da atividade humana e não-humana são
registrados no espaço vivido, mas somente se pensarmos na es-
crita não como uma composição verbal, mas como um tecido de
linhas - não como um texto, mas como textura. 'Atividade prá-
tica escreve na natureza', ele comenta, 'numa mão que rabisca'.
Pensa nas trilhas reticulares deixadas pelas pessoas e animais na
medida em que caminham por seus negócios em torno da casa,
povoado e cidade. Apanhados nestes múltiplos emaranhados,
cada monumento ou edifício, visto em seu contexto e entorno,
é mais 'archi-textural' do que arquitetural. (INGOLD, 2011,
p. 84 , tradução nossa)

Ao sobrepor as linhas de circulação das crianças nos arredores da Barragem Santa Lúcia aos dados sobre a densidade de cenas com crianças, representamos - a título de síntese da observação da presença e da circulação das crianças nos arredores da Barragem Santa Lúcia - o mapa etno-gráfico da Figura 11. Essas imagens deram elementos para desenvolvimento de outros procedimentos da pesquisa, ou seja, as entrevistas informais com os sujeitos adultos envolvidos nesta pesquisa: usuários do parque, comerciantes, diretores e educadores das escolas e de projetos socioculturais locais, agentes de ONGs, associaçóes do Morro e dos bairros, policiais e planejadores urbanos, dentre outros. Diante de propostas que vem 
sendo desenvolvidas de integração das atividades escolares com os demais espaços e tempos da cidade - como a proposta da Escola Integrada, implementada pela Secretaria Municipal de Educação de Belo Horizonte - a ferramenta desenvolvida se mostra como um instrumento que pode aportar contribuiçóes para as análises e planejamentos a serem desenvolvidos.

Esses mapas etno-gráficos são apenas algumas das possibilidades de aplicação de filtros às planilhas e seus resultados na representação gráfica em termos de densidade de cenas com crianças. Demonstram o potencial da ferramenta do geoprocessamento, associada à interface com programas do tipo Google Earth (que disponibiliza uma imagem fotográfica de fundo e, portanto, facilita o reconhecimento do local) em uma etno-grafia. Outras possibilidades de cruzamento de dados e análise poderiam ser experimentadas a partir desse processo, tais como acrescentar dados demográficos, dados qualitativos associados aos pontos que representam os diversos equipamentos, associação de fotos, textos e cruzar com informaçôes que os diversos atores achassem pertinentes - inclusive, e especialmente, as próprias crianças.

Evidentemente o universo investigativo aqui contemplado - o estudo e registro dos usos dos espaços públicos por 11 crianças moradoras da favela da região - é necessariamente circunscrito. No entanto, a riqueza dos dados obtidos, ao conferir visibilidade às distinçóes não apenas de classe social, mas de gênero e idade permitem-nos fornecer elementos para a melhor compreensão dos usos distintos dos espaços urbanos.

\section{Figura 10}

Fluxos de circulação das crianças do Morro pela Barragem Santa Lúcia

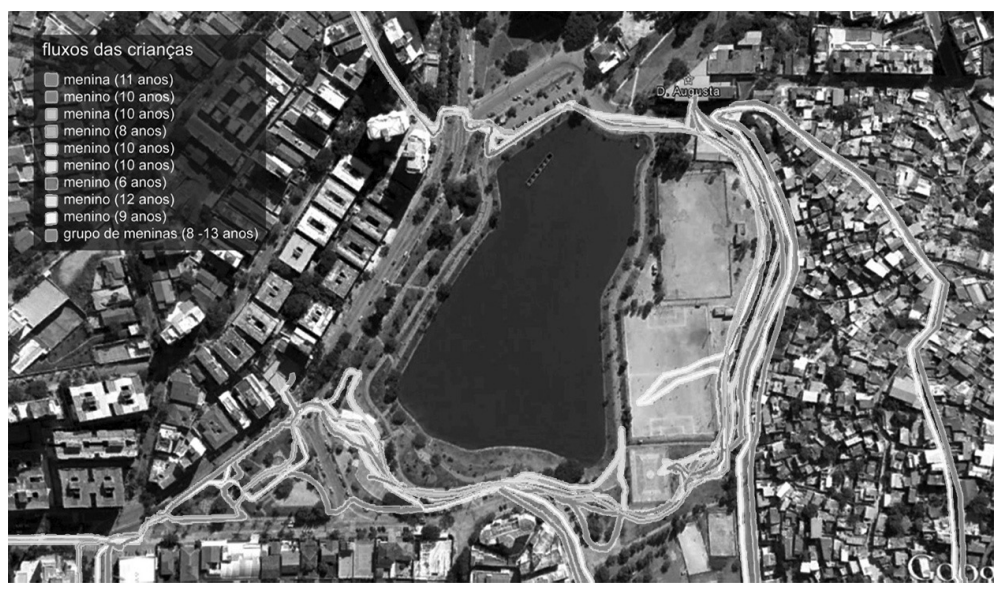

Fonte: Elaboração própria, através do programa Google Earth. 


\section{Figura 11}

Presença e circulação das crianças na Barragem Santa Lúcia

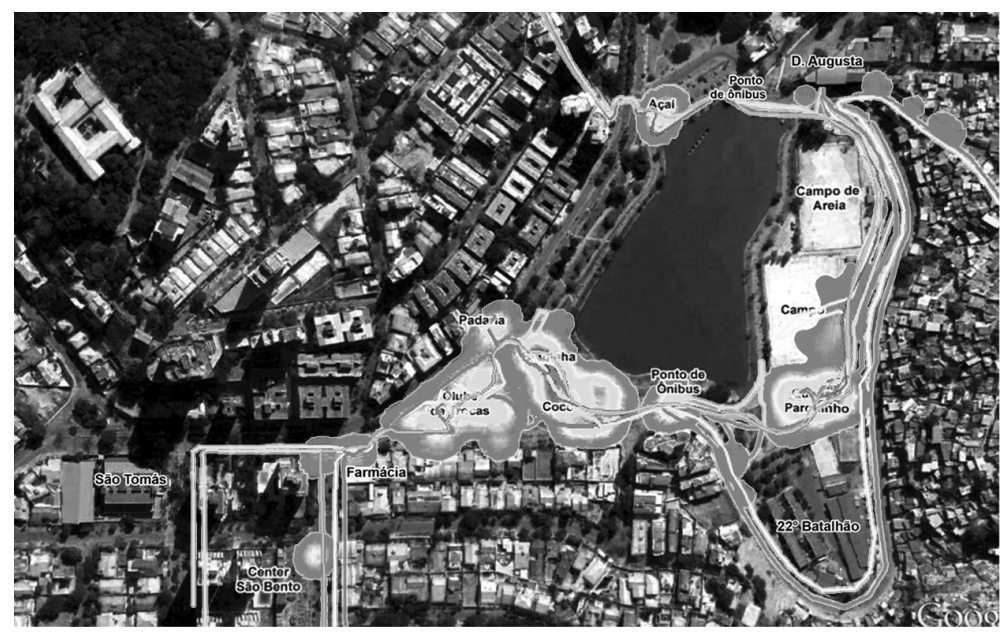

Fonte: Elaboração própria, através do programa Google Earth.

\section{Considerações finais: uma cartografia dos espaços com crianças nos arredores da Barragem Santa Lúcia}

Os mapas etno-gráficos apresentados são apenas algumas das possibilidades de aplicação de filtros às planilhas e seus resultados na representaçáo gráfica em termos da recorrência de cenas observadas. Ao desenvolver ferramentas de leitura e de registro gráfico do mundo urbano nesta pesquisa, tentou-se contribuir para a exploração das possibilidades e potencialidades que esse tipo de instrumento - ao focar nos usos que as pessoas fazem destes espaços - pode revelar.

$\mathrm{O}$ potencial da ferramenta do geoprocessamento, associada à interface com programas do tipo Google Earth em processos de planejamento espacial e em uma etno-grafia espacializada levanta diversas possibilidades de ulteriores desenvolvimentos da própria ferramenta e de suas possíveis utilidades. Outras possibilidades de cruzamento de dados e análise podem ser experimentadas a partir desse processo. Foi possível considerar ainda que essa metodologia pode ser experimentada por distintos atores e pesquisadores de diversos campos, até mesmo em outros contextos e recortes espaciotemporais, distintos do adotado. Esse experimento procurou produzir uma ferramenta interativa, através da qual se pudesse dar expressão às percepçóes e demandas dos diferentes atores, com 
especial atenção ao modo de circulação e uso dos espaços urbanos próprios das crianças.

As informaçóes tornadas visíveis nos mapas podem ser um interessante instrumento para provocar interaçóes entre os diferentes campos de políticas para a infância. Podem sugerir uma maior integração entre programas e políticas públicas urbanas e de atenção à infância. Podem suscitar uma maior atenção na produção dos espaços urbanos pelos quais as crianças circulam, por exemplo, os trajetos entre as escolas, indicados pelos próprios sujeitos como corredores preferenciais nos quais a presença poderia ser cuidada, acompanhada e potencializada. Enfim, os mapas tornam visível a presença das crianças na cena urbana, e desafiam a lógica contemporânea de quase completa institucionalização da vida infantil na cidade.

Com base no conjunto de dados produzidos, foi possível considerar que a infância toma expressão nos espaços da cidade - apesar da percepção de sua inadequação - e que, portanto, requer atenção específica dos estudiosos e planejadores. Essa perspectiva, ao imprimir atenção às especificidades dos sujeitos e não somente das questóes macroestruturais (economia, transporte, segurança, dentre outras), pode contribuir para uma inversão na lógica do planejamento dos espaços - nesse caso, a partir das crianças.

\section{Notas}

1. Tais campos buscam apreender a criança como sujeito social, que na relação com o mundo adulto produz formas singulares de apreensão e significação, configurando uma cultura infantil a partir das interaçôes com adultos e crianças em distintos espaços e tempos sociais. Veja-se: Corsaro (2011), Corsaro; Qvroutrup; Haning (2010), Sarmento (2008).

2. Veja-se, entre outros, Vasconcellos e Sarmento (2007), Debortoli; Martins; Martins (2008), Muller $(2006,2012$ e 2014).

\section{Referências}

ASSOCIAÇÃO INTERNACIONAL DE CIDADES EDUCADORAS. Disponível em http://w10.bcn.es. Extraído em 30 de dezembro de 2013.

CALDEIRA, T. Cidade de muros; crime, segurança e cidadania em São Paulo. São Paulo: Editora 34/ Edusp, 2000.

CIDADE ESCOLA APRENDIZ. Disponível em http://cidadeescolaaprendiz.org.br. Extraído em 30 de dezembro de 2013.

COHN, C. A Antropologia da criança. Rio de Janeiro: Zahar, 2005. 
CORSARO, W. A. A reprodução interpretativa no brincar ao 'faz-de-conta' das crianças. Educação, Sociedade \& Culturas, Porto, n. 17, p. 113-134, 2002.

CORSARO, W. Sociologia da infância. Porto Alegre: Artmed, 2011

DE CERTEAU, M. A invenção do cotidiano. v. 1. Artes de fazer. 6. ed. Petrópolis: Vozes, 1994 [1990].

DEBORTOLI, J. A.; MARTINS, M. F.; MARTINS, S. Infâncias na metrópole (Org). Belo Horizonte: Editora da UFMG, 2008.

DElGADO, A. C. C.; MÜlleR, F. (Orgs.). Dossiê: Tempos e Espaços das Infâncias. Currículo sem Fronteiras, Porto Alegre, v. 5, n. 1, jan./jun. 2006.

FERNANDES, F. As trocinhas do Bom Retiro: contribuição ao estudo folclórico e da sociologia da criança e dos grupos infantis. Proposiçôes, Campinas, v. 15, n. 1 (43) jan./ abr. 2004

FERRO, S. O canteiro e o desenho. São Paulo: Projeto Editores Associados, 1979.

GEERTZ, C. A interpretação das culturas. Rio de Janeiro: Zahar, 2003 $\overline{1997 .}$

. O saber local: novos ensaios em antropologia interpretativa. Petrópolis: Vozes,

GOFFMAN, E. The presentation of self in everyday life. Nova York: Anchor Books, 1959.

GOOGLE EARTH. Disponível em http://www.google.com/earth/. Acesso em 22 out. 2011.

GULLØV, K. F.; OLWIG, E (Eds.). Children's Places: cross-cultural perspectives. Londres: Routledge, 2003.

INGOLD, T. The perception of the environment: essays in livelihood, dwelling and skill. London: Routledge, 2000.

2011 .

. Being alive: Essays on Movement, Knowledge and Description. Oxon: Routledge,

LEFEBVRE, H. O direito à cidade. São Paulo: Centauro, 2009 [1968].

LEFEBVRE, H. The production of space. Oxford: Blackwell Plubishers, 1991 [1974].

LOPES, J. T. Andante, andante: tempo para andar e descobrir o espaço público. Revista da Faculdade de Letras da Universidade do Porto: Sociologia, Porto, v. 17/18, n. 1, p. 69-80, 2007/2008.

MAGNANI, J. G. C. Festa no pedaço: cultura popular e lazer na cidade. São Paulo: Brasiliense, 1984.

Quando o campo é a cidade: fazendo antropologia na metrópole. In: MAGNA-

NI, J. G. C.; TORRES, L. L. (Orgs.). Na metrópole: textos de antropologia urbana. 2. ed. São Paulo: EDUSP/FAPESP, 2000.

. De perto e de dentro: notas para uma etnografia urbana. Revista Brasileira de

Ciências Sociais. São Paulo, vol. 17, n. 49, p. 11-29, jul. 2002. 
MULLER. F. Infância e Cidade: Porto Alegre através das lentes das crianças. Educaçâo e Realidade, Porto Alegre, v. 37, p. 295-318, 2012.

; NASCIMENTO, M. L. B. P. (Org.). Dossiê 'Estudos da Infância. Brasília: Linhas

Críticas, Revista da Faculdade de Educação da UnB, Brasília, v. 20, n. 41, 2014.

PARGA, J. S. Orfandades infantiles y adolescentes: introducción a uma sociologia de la infância. Quito: Abya-Yala, 2004.

QVROUTRUP, J.; CORSARO, W.; HONING, M. (Org.). The Palgrave Handboock of childhood studies. London, Palgrave Macmimillian, 2009.

SARMENTO, M.; GOUVÊA, M. C. (Org.). Estudos da infância: educação e práticas sociais. Petrópolis: Vozes, 2008.

SENNETT, R. O declinio do homem público: as tiranias da intimidade. São Paulo: Companhia das Letras, 1988 [1974].

SILVA, R. C. Circulando com os meninos: infância, participação e aprendizagens de meninos indígenas Xakriabá. 2011. Tese (Doutorado em Educação) - Faculdade de Educação, Universidade Federal de Minas Gerais, Belo Horizonte, 2011.

SOJA, E. W. Postmetropolis: critical studies of cities and regions. Oxford: Backwel, 2000.

VASCONCELOS V.; SARMENTO, M. (Org.). Infâncias invisiveis. Araraquara: Junqueira \& Marin, 2007.

Recebido em 29 de abril de 2014.

Aprovado em 24 de outubro de 2014. 